\title{
IMPROVEMENTS OF ALVEOLAR BONE HEALING USING MORINGA OLEIFERA LEAF POWDER AND EXTRACT BIOMIMETIC COMPOSITE: AN EXPERIMENTAL STUDY IN DOGS
}

\author{
Rania A. A. EI behairy*, Nehad A. Ramadan**, Dalia El Rouby ${ }^{* * *}$ and Ibrahim H. Ahmed ${ }^{* * * *}$
}

\begin{abstract}
Alveolar ridge preservation techniques and biomaterials were extensively used in the past few years. The rate of new bone formation is the concept in healing sockets. The faster the rate the lesser the alveolar bone resorption. Resorption is fastened in the first three months after extraction. Wide range of biomaterials were available, the choice of an ideal material was confusing.
\end{abstract}

Objective: Evaluate the effectiveness of both Moringa Oleifera (MO) leaf powder and extract mixture locally and MO leaf extract repeated injections in fresh extraction sockets of dog. Moreover, identifying bioactive phenolic compounds in dried leaves.

Materials and Methods: Eight mongrel dogs were included in this study; two animals were used as control. Six test animals were divided into two groups according to biopsy time (3 and 5 weeks). Each of these groups includes three animals. All animals were subjected to extraction of the third premolar bilaterally, both sides of the test animals (the six) were treated with Moringa Oleifera leaf powder $(0.7 \mathrm{gm})$ and water extract $(1 \mathrm{ml})$ mixture. The right side only was subjected to repeated injections of Moringa Oleifera leaf water extract $(1 / 2 \mathrm{ml})$ for two times $\left(1^{\text {st }}\right.$ week and $2^{\text {nd }}$ week postoperatively for all groups). Trephine bur was used to take biopsy for the purpose of histopathologic examination by H\&E and Masson Trichrome stain to quantify new bone formation, and number of inflammatory cells.

Results: Bone area percent showed the highest mean value in the right side at 3 weeks and 5 weeks. ANOVA test revealed no significant difference between groups $(\mathrm{P}=0.43)$ at 3 weeks, while the difference was significant at 5 weeks $(\mathrm{P}=0.00)$. Mean inflammatory cells count were significantly higher mean value in control group at 3 weeks and 5 weeks $(\mathrm{P}=0.00)$.

Conclusion: Two injections of moringa oleifera aqueous extract of $11.7 \%$ concentration improved bone area present significantly at 5 weeks and decreased inflammatory cells at all test periods.

KEYWORDS: Extraction sockets, ridge preservation, Moringa Oleifera leaf aqueous extract, green synthesis and dogs.

\footnotetext{
*Oral and Maxillofacial Surgery Department, Faculty of Oral and Dental Medicine, Badr University, Egypt. ** Poultry Nutrition research department, Animal production research Institute, Agriculture research center, Egypt. *** Oral pathology department, Faculty of Oral and Dental Medicine, Cairo University, Egypt. ****Surgery, Anesthesiology, and Radiology, Faculty of Veterinary medicine, Suez Canal University, Egypt.
} 


\section{INTRODUCTION}

Alveolar bone resorption is unavoidable process Once the tooth extracted, clinical bone loss follows, especially in the first 3 months. Essential problems for restorative and implant dentistry appear at the extraction site. Maintenance of alveolar bone is mandatory. Numerous biomaterials have been tried as bone substitutes to maintain alveolar bone after extraction. However, there use is still doubtful because it can interfere with healing process. ${ }^{1,2}$

Natural materials have the advantages to be cheap, biocompatible and available. Several herbs could be used for decreasing inflammatory response and stimulating bone healing. Promising herbal examples include: Cissus quadrangularis, Bambusa arundinacea, Soy bean, Mate tea, Grape seeds, Ellagic acid and Moringa oleifera (MO). They were tested by animal feeding, intragastric lavage and local administration. ${ }^{3-5}$ Ayurveda: the ancient science of medicine describes various herb preparations that achieve faster bone healing. Cissus quadrangularis improved bone density and shorten the osseointegration around implant. Bambusa arundinacea and Soy bean were used for dry socket healing. ${ }^{5}$ Mate tea, was used in fresh extraction sockets in rat model. ${ }^{4}$

Moringa species have 14-17 subtypes, Moringa oleifera Lam is the one grows locally, known as the miracle tree, because it contains various nutrients, and phytochemicals as illustrated in (Table 1). ${ }^{6}$ As regard inorganic components (Calcium, Phosphorus, Magnesium) increase bone density and strength. Magnesium $(\mathrm{Mg})$ affects the bone cells activities and bone homeostasis. ${ }^{7-10}$

Most studies have focused on the leaves of the plant. Moringa oleifera leaf (MO) have been confirmed for antioxidant, anti-inflammatory, anticancer, and antimicrobial properties. ${ }^{11}$ It can decrease pro-inflammatory mediators (prostaglandin synthesis and nitrous oxide production RNS in macrophages cells). MO plant have been proved to possess the osteoprotective potency. ${ }^{12} \mathrm{MO}$ leaves known to treat many chronic diseases. ${ }^{13}$ Especially diabetic patient as insulin deficiency has direct effects of on bone. In other words, MO being antidiabetic stimulates bone density and strength. ${ }^{14-17}$

Polyphenols and flavonoids (phytochemicals) were the main chemical ingredient in $\mathrm{M}$. oleifera leaves, which proved stimulant effects on osteoblast proliferation and differentiation, besides inhibitory effect on osteoclasts. ${ }^{1}$ The Moringa leaf extract has indirect osteoinductive properties because of its numerous polyphenolic contents (Table: 1,2$)^{6}$. As a result, the number of osteoclasts will decrease, and subsequently bone resorption decreases and bone formation progresses.

TABLE (1) Nutritional contents per 100gm of Moringa oleifera leaves dried powder ${ }^{6,8}$

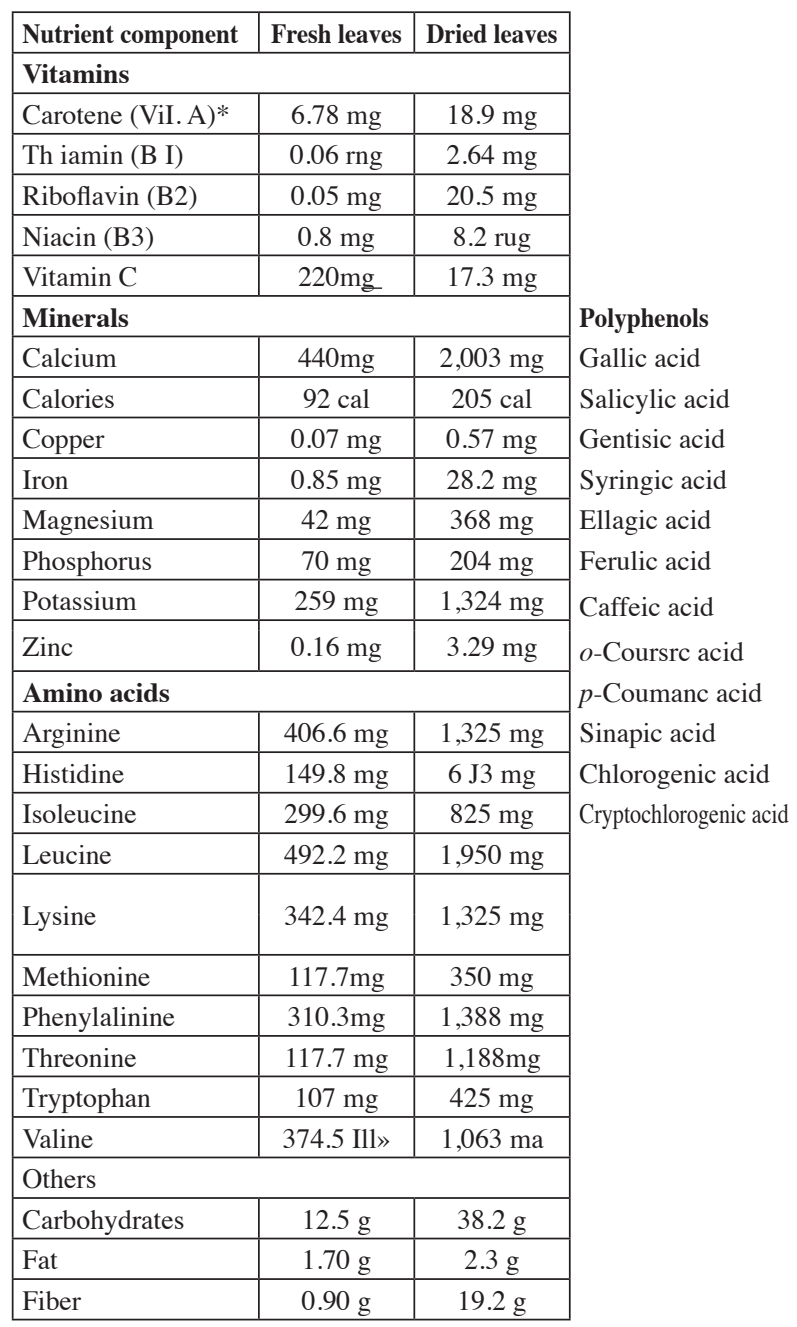


TABLE (2) Showing superior polyphenols and flavonoid yields of water extract ${ }^{16}$

\begin{tabular}{cccc}
\hline Extracts & Yield (\%) & $\begin{array}{c}\text { Polyphenols } \\
\left(\mathrm{mg} \mathrm{GAEt}^{1} / \mathrm{g}\right)\end{array}$ & $\begin{array}{c}\text { Flavonoids } \\
\left(\mathrm{mg} \mathrm{RHE}^{2} / \mathrm{g}\right)\end{array}$ \\
\hline Water & $13.17 \pm 0.01^{3), 04)}$ & $58.04 \pm 1.58^{\mathrm{a}}$ & $12.36 \pm 0.53^{\mathrm{a}}$ \\
Ethanol & $7.48 \pm 0.00^{\mathrm{c}}$ & $40.72 \pm 1.53^{\mathrm{c}}$ & $10.03 \pm 0.3 \mathrm{~d}^{\mathrm{b}}$ \\
Methanol & $9.54 \pm 0.01^{\mathrm{b}}$ & $47.15 \pm 0.94^{\mathrm{b}}$ & $10.64 \pm 0.11^{\mathrm{b}}$ \\
\hline
\end{tabular}

\section{MATERIALS AND METHODS}

\section{Materials}

The fresh leaves of Moringa oleifera (MO) were harvested from Agriculture research center, Egypt. The leaves were soaked for $15 \mathrm{~min}$.in water to remove dirt and dried (to low moisture content of 6-7\%) for seven days under shade, at room temperature, to avoid loss of active compounds. The dried leaves were stored in air tight container at $7^{\circ} \mathrm{C}$. The stored leaves were ground to powder using home grinder at the same day of use. For preparing aqueous extracts, macerate the dried leaf powder 40 gm in $100 \mathrm{ml}$ boiled water with stirring and then left for $24 \mathrm{~h}$ at room temperature. The extract was obtained by filtration. Filtrate was concentrated using an evaporator to $11.7 \%$ of their initial volume (Fig.2 A). High performance liquid chromatography (HPLC) was used to estimate the flavonoid and polyphenols in the mixture and extract.

\section{High performance liquid chromatography (HPLC)}

This was done in the central laboratories, Centers of Excellence, Chromatography Lab, National Research Center, Egypt. HPLC analysis was carried out using an Agilent 1260 series. The separation was carried out using Kromasil C18 column (4.6mm x $250 \mathrm{~mm}$ i.d., $5 \mu \mathrm{m})$. The mobile phase consisted of water (A) and $0.1 \%$ tri-floroacetic acid in acetonitrile (B) at a flow rate $1 \mathrm{ml} / \mathrm{min}$. The mobile phase was programmed consecutively in a linear gradient as follows: 0 min $(82 \% \mathrm{~A}) ; 0-5$ $\min (80 \% \mathrm{~A})$; $5-8 \min (55 \% \mathrm{~A}) ; 8-12 \min (55 \% \mathrm{~A})$;
$12-15 \min (85 \% \mathrm{~A})$ and $15-16 \min (80 \% \mathrm{~A})$. The multi-wavelength detector was monitored at 280 $\mathrm{nm}$. The injection volume was $10 \mu \mathrm{l}$ for each of the sample solutions. The column temperature was maintained at $35^{\circ} \mathrm{C}$.

\section{Experimental animals}

The experimental study was performed at the Department of Surgery, Anesthesiology, and Radiology, Faculty of Veterinary Medicine, Suez Canal University, Egypt. Eight animals were included. Two control and Six test adult healthy male mongrel dogs with an average weight of 10-15 kg, comparable age (about 1year were included in this study. The six animals were divided into 2 groups according to the time of biopsy ( 3 and 5 weeks). Each of these groups includes three animals.

\section{Surgical procedures}

All experimental dogs were operated under general anesthesia (GA). Each animal was premedicated with Valpam IM (product of AMOUN Pharmaceutical Industries CO (APIC) S.A.E El Salam city, Cairo, Egypt) in a dose of $0.5 \mathrm{mg} / \mathrm{Kg}$ body weight 10-15 minutes; prior to induction anesthesia.Cannulation and injection of prophylactic antibiotic were carried out with Flumox 500 mg, 2ml IV (Egyptian International Pharmaceutical Industries CO (EIPICO) 10Th of Ramadan city, Egypt), followed by Fortecortin 2ml IM (product of GALAXCO Pharmaceutical Industries CO. El Salam city, Cairo, Egypt). Furthermore; induction anesthesia was achieved using IV administration of Sodium Thiopental IV (Egyptian International Pharmaceutical Industries CO (EIPICO) $10^{\text {th }}$ of Ramadan city, Egypt), (20-30 mg/kg body weight in dilution of $2.5 \%$ solution). General anesthesia was maintained using again IV Sodium Thiopental.

Animals were subjected to extraction of the third premolar bilaterally (Fig.1). The crown was hemisected vertically with tungsten carbide fissure bur. Elevators were used to extract roots without 
trauma to the alveolar bone. The empty tooth socket was irrigated with saline solution. Both sides were treated with moringa oleveira leaf powder $(0.7 \mathrm{gm})$ and exctract (1ml) mixture (Fig.2 B \& Fig.3 A,B). The mixture is enough for three sockets. Releasing incisions followed for tension-free wound closure using 3/0 Vicryl sutures (Fig.3C). Repeated injection administrated weekly in the first 2 weeks at the right side only. Suitable gauge needle was used for extract injection at the center of distal socket (Fig.3D)

Postoperative therapy including analgesic nonsteroidal anti-inflammatory; Cataflam $75 \mathrm{mg} / 2 \mathrm{ml}$ IM Cataflam 75mg IM (Novartis Pharma, Pharmaceutical industries Co, Cairo, Egypt) and antibiotic Flumox 500 were systemically administrated to the operated dog once a day for three successive days.

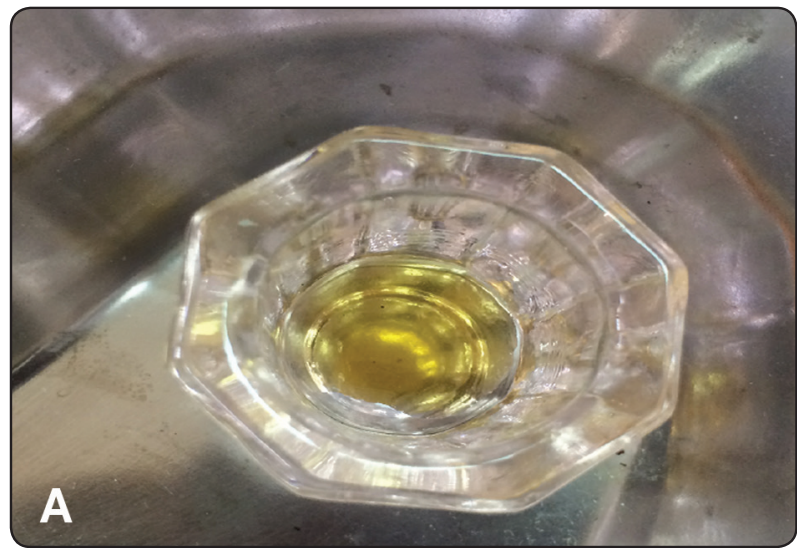

Fig. (2A) Showing moringa oleveira exctract (1 ml. at $11.7 \%$ conc.)
Animal sacrifice was done by rapid IV injection of overdose Sodium Thiopental at 3 weeks and 5 weeks postoperatively, the mandibles was dissected, sectioned and stored in neutral formalin $10 \%$.

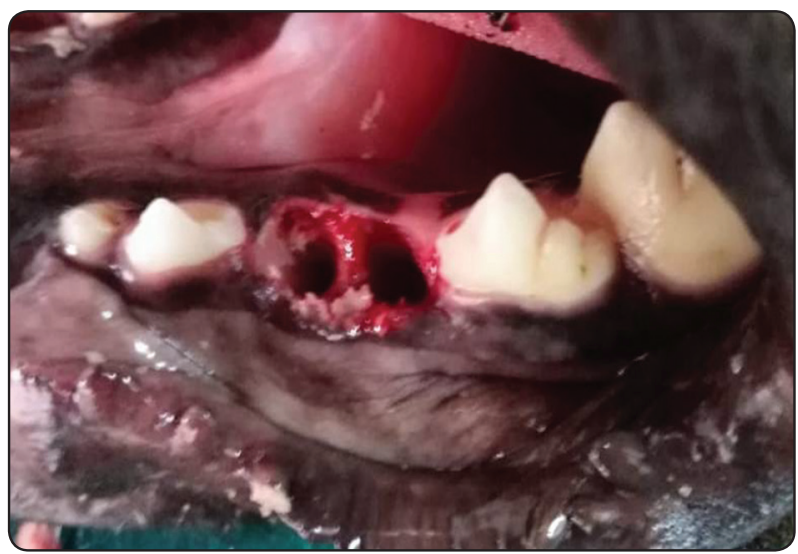

Fig. (1) Showing sockets of extracted third premolar.

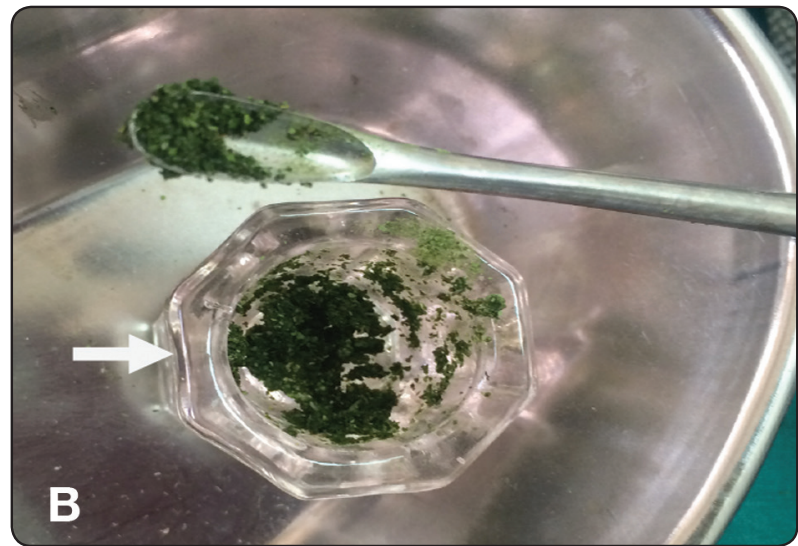

Fig. (2B) Moringa oleveira leaf powder $(0.7 \mathrm{gm})$ and exctract mixture (white arrow).
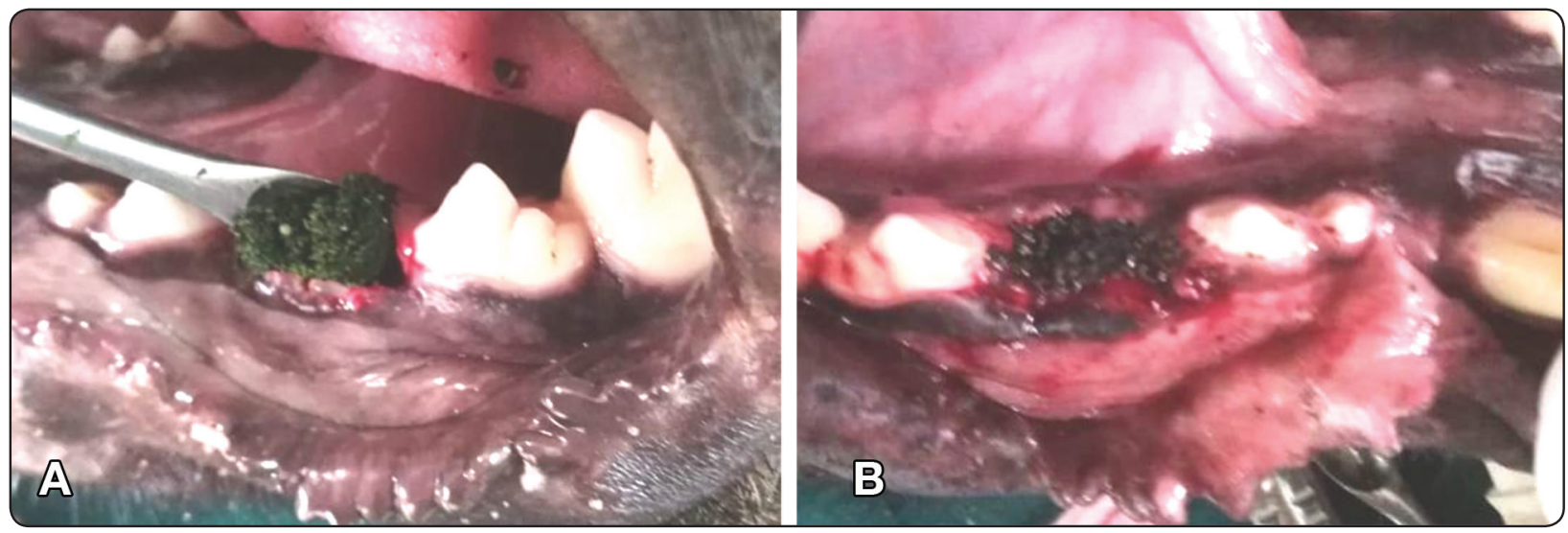

Fig. (3) Showing: A\&B: Application of moringa oleveira leaf powder and exctract mixture. 


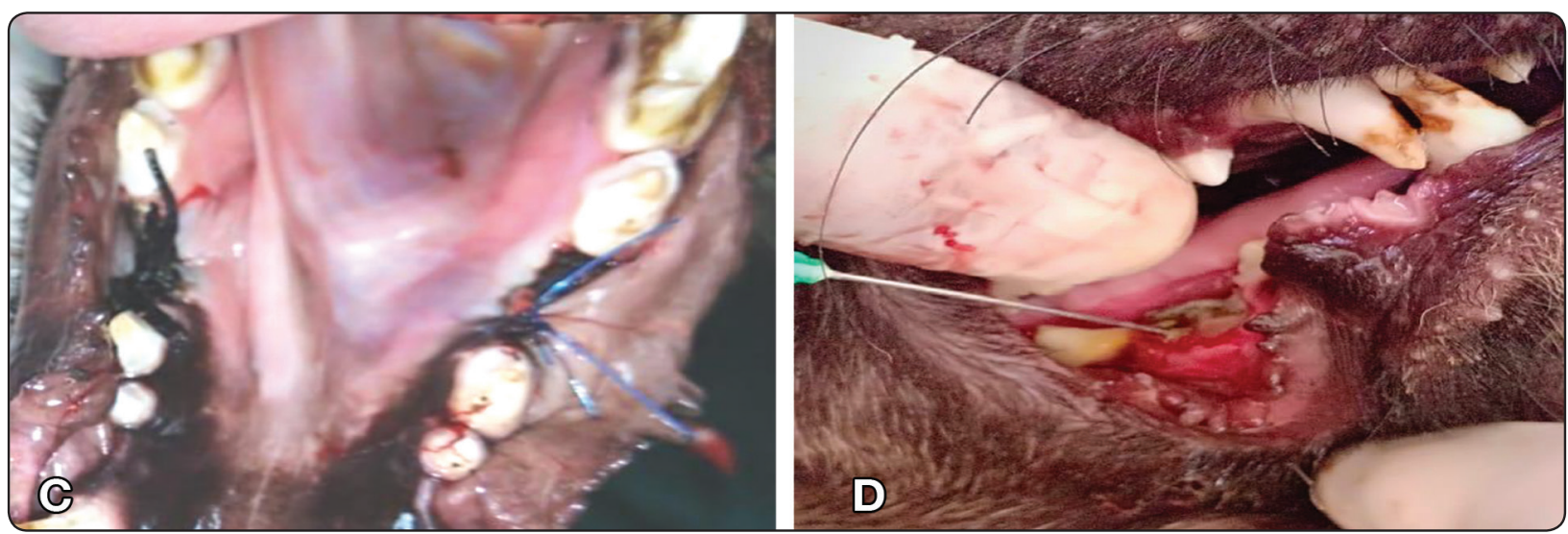

Fig. (3) C: Interrupted sutures for both sides. D: Repeated injection.

Specimen preparation for microscopic examination

The samples were prepared and analyzed at Oral Pathology Unit, Pathology department, Faculty of Oral and Dental Medicine, Cairo University. Bone biopsies obtained from the center of the socket were decalcified in EDTA for four weeks. After decalcification, tissue blocks were processed and embedded in paraffin. Five-micron sections were cut perpendicular to the bone surface, mounted on glass slides, deparaffinized, hydrated, and stained with hematoxylin and eosin (H\&E) stain Fig.(4) and Masson trichrome stain Fig.(5) for histological evaluation and histomorphometric analysis.

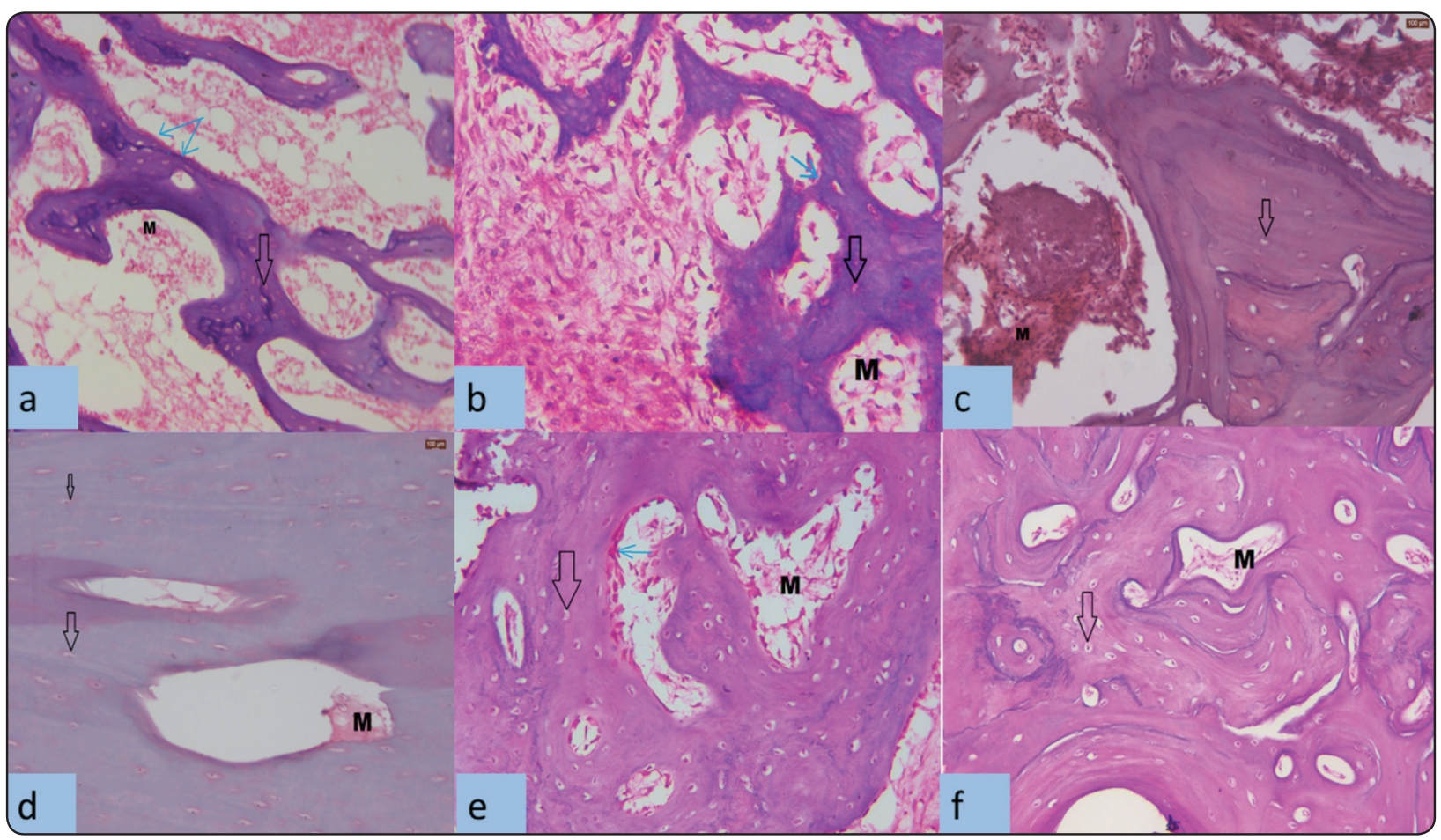

Fig. (4) H\&E stained sections showing newly formed bone with viable osteocytes entrapped in lacunae (black arrow), Osteoblastic rimming (blue arrows) and fibrovacular marrow spaces (M) after 3 weeks in control (a), left side (b) and right side (c) \& after 5 weeks in control (d), left side (e) and right side (f), (original magnification x 200). 


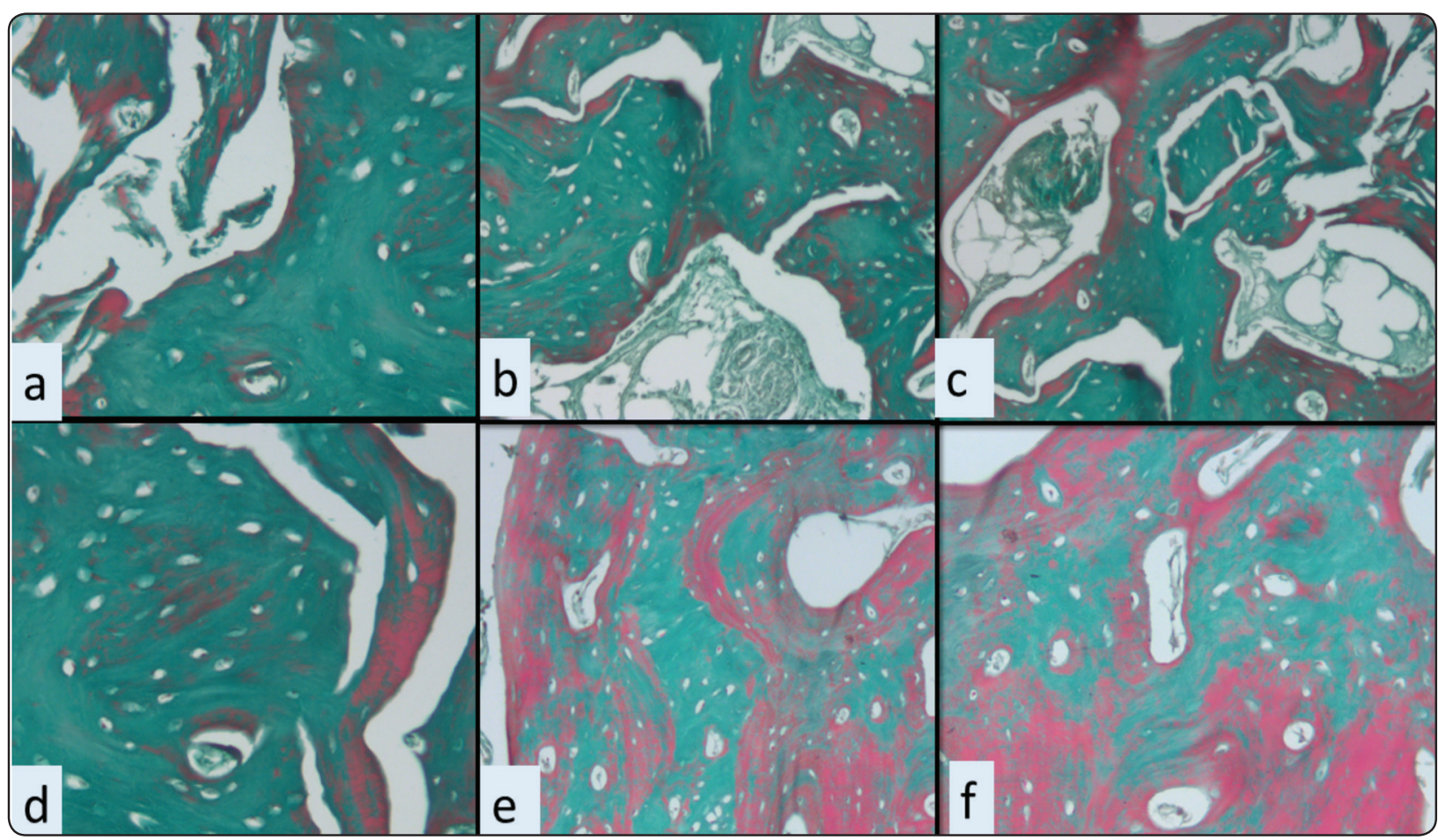

Fig. (5) Masson trichrome stained sections showing areas occupied by collagen fibers and newly formed osteoid tissue (blue-green color) and calcified osseous tissue (red color) after 3 weeks in control (a), left side (b) and right side (c) \& after 5 weeks in control (d), left side (e) and right side (f), (original magnification x 200).

\section{Measuring the area percent (\%) of newly-formed bone (histomorphometric analysis)}

The area percent (\%) of the newly-formed bone in H\&E stained sections was estimated by Leica Qwin 500 analyzer computer system, (Leica Microsystems, Switzerland). Using a magnification of $\times 200$, the cursor was used to outline the areas of newly-formed bone trabeculae, where these areas became masked by a binary blue color measurable by the computer. The image analyzer was calibrated to automatically convert the measurement units (pixels) produced by the image analyzer program into actual micrometer units. The number of inflammatory cells was manually counted in 3 different high power fields (X400) in each slide and the mean was calculated.

\section{RESULTS}

\section{1- Results of the microscopic examination}

Control group: H\&E-stained sections, revealed the presence of irregular osteoid bone intermingled with organized collagen fiber bundles. Bone formation started from the socket border towards the center, with no evidence of bone regeneration at the center. Lacunae containing osteocytes were scattered within the newly formed bone trabeculae whereas osteoblasts rimmed their trabeculae borders. Fibrovascular marrow were seen observed in between the newly-formed trabeculae. Mild chronic inflammatory cell infiltration was noted within the fibrous tissue. Bone formation was more noted at 5 weeks in comparison to 3 weeks. Masson trichrome stained sections demonstrated collagen fibers and newly formed osteoid tissue (blue-green color) at both observation times 


\section{Experimental groups}

Microscopic examination of the left side group at 3 weeks revealed partial obliteration of the bony defect with dispersed irregularly arranged bone trabeculae, separated by fibrovascular marrow. The initial bone formation started at the socket borders. At the socket's periphery, the bone trabeculae were seen coalescing together in certain areas, but separated by marrow spaces in other sites. Randomly arranged osteocytes were embedded within the trabeculae. No sign of residual material could be detected in any of the prepared specimens. Spare inflammatory cells were occasionally observed. At 5 weeks, bone trabeculae filled most of the socket space.

Microscopic examination of the right side group at 3 weeks revealed that the deposition of osteoid newly formed bone trabeculae started from the socket border, growing through the empty socket. The bone trabeculae were thick and regularly arranged, separated by bone marrow spaces and surrounded by an osteoblastic layer. Lacunae containing osteocytes were detected within the trabeculae. The newly formed bone consisted mainly of woven bone with some more mature lamellar bone apparent. The evident merging of woven and mature bone trabecula indicated that the maturation process was in progress. No inflammatory cell infiltrate was present in most fields. At 5 weeks, the socket space was almost completely filled with newly formed bone. In the experimental groups, Masson trichrome stained sections demonstrated collagen fibers and newly formed osteoid tissue (blue-green color) at 3 weeks, while more mature mineralized bone was evident at 5 weeks (red color).

\section{Statistical analysis}

The data obtained from computer image analysis as well as the number of inflammatory cells were represented as mean values and standard deviations (SD). Statistical analysis was performed using Statistical Package for Scientific Studies \#19 (SPSS, Inc., Chicago, IL, USA). The paired t-test was used for statistical analysis of the differences between the 2 observation times within the same group. ANOVA test was used to compare the 3 study groups. This was followed by Tukey's post hoc test when ANOVA revealed a significant difference. A value of $p \leq 0.05$ was considered statistically significant.

\section{2- Statistical results}

Bone area percent showed the highest mean value in the right side at 3 weeks and 5 weeks. ANOVA test revealed no significant difference between groups $(\mathrm{P}=0.43)$ at 3 weeks, while the difference was significant at 5 weeks $(\mathrm{P}=0.00)$. Tukey's post $\mathrm{HOC}$ test revealed no significant difference between control and left side at 5 weeks. ANOVA test revealed that Mean bone area percent increased by time between 3 and 5 weeks in all groups. Paired $\mathrm{t}$ test revealed that the difference was statistically significant in control $(\mathrm{P}=0.01)$, left side $(\mathrm{P}=0.01)$ and right side $(\mathrm{P}=0.00)$. (Tables 3, 4 and 5) (Fig.6)

\section{Inflammatory cells numbers in high power} field (HPF) recorded highest mean value in control group. ANOVA test revealed a significant difference between groups $(\mathrm{P}=0.00)$ at 3 weeks and 5 weeks. Tukey's post hoc test revealed no significant difference between left and right side in the two test periods. Mean inflammatory Cells number/ HPF decreased by time in all groups between 3 and 5 weeks. Paired t test revealed that the difference was not statistically significant. (Tables 3, 4 and 5) (Fig.7) 
TABLE (3) Comparison of histological results between groups at 3 weeks (ANOVA test)

\begin{tabular}{|c|c|c|c|c|c|c|c|c|c|c|}
\hline Bone naran & & Mean & Std Dev & Std. & $\begin{array}{l}95 \% \mathrm{C} \\
\text { Interval }\end{array}$ & $\begin{array}{l}\text { idence } \\
\text { r Mean }\end{array}$ & Min & Max & $\mathrm{F}$ & P \\
\hline Bone parar & & Mean & Sta. Dev & Error & $\begin{array}{l}\text { Lower } \\
\text { Bound }\end{array}$ & $\begin{array}{l}\text { Upper } \\
\text { Bound }\end{array}$ & Minn & $\operatorname{Max}$ & $\mathrm{F}$ & $P$ \\
\hline & Control & $47.97^{\mathrm{a}}$ & 5.61 & 2.29 & 42.08 & 53.85 & 40.10 & 56.10 & & \\
\hline Area percent of & $\mathrm{L}$ & $44.76^{b}$ & 2.52 & 1.03 & 42.12 & 47.40 & 41.10 & 47.20 & 38.41 & $0.43 \mathrm{~ns}$ \\
\hline & $\mathrm{R}$ & $51.61^{\mathrm{a}}$ & 1.76 & .72 & 49.76 & 53.46 & 49.70 & 54.80 & & \\
\hline Number of & Control & $6.50^{\mathrm{a}}$ & .55 & .22 & 5.93 & 7.07 & 6.00 & 7.00 & & \\
\hline Inflammatory & $\mathrm{L}$ & $2.83^{\mathrm{b}}$ & .98 & .40 & 1.80 & 3.87 & 2.00 & 4.00 & 37.34 & $0.00 *$ \\
\hline Cells/HPF & $\mathrm{R}$ & $3.00^{\mathrm{b}}$ & .89 & .37 & 2.06 & 3.94 & 2.00 & 4.00 & & \\
\hline
\end{tabular}

Significance level $P \leq 0.05$, * significant

Tukey's post hoc test: Within the same comparison: means sharing the same superscript letter are not significantly different

TABLE (4) Comparison of histological results between groups at 5 weeks (ANOVA test)

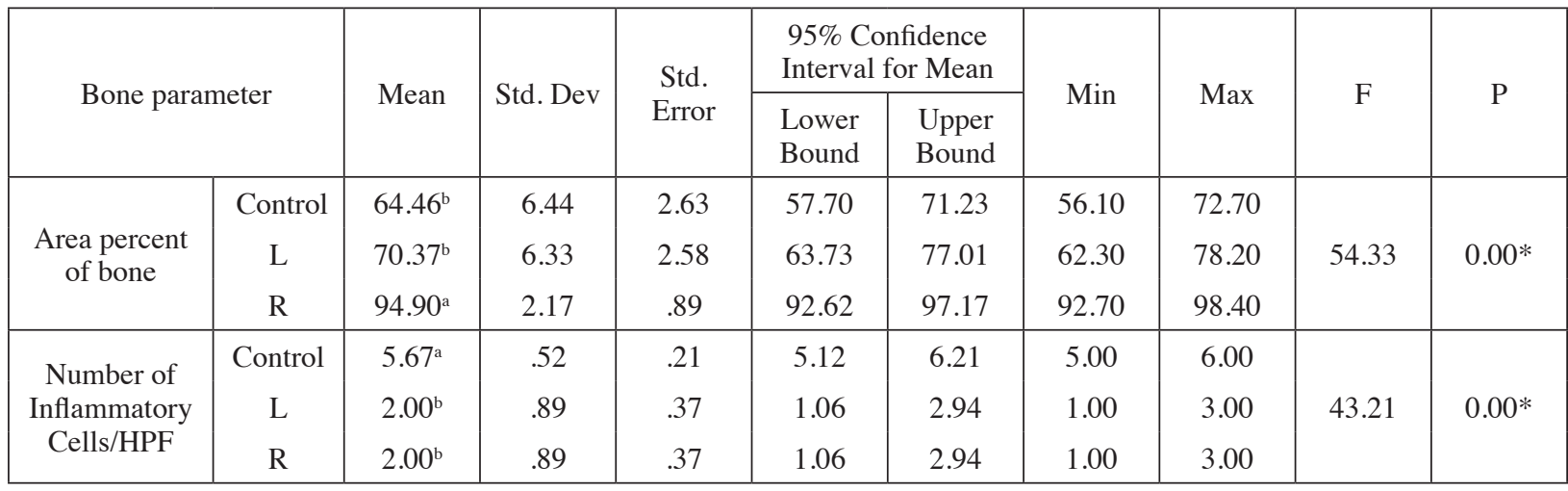

Significance level $P \leq 0.05$, * significant

Tukey's post HOC test: Within the same comparison: means sharing the same superscript letter are not significantly different

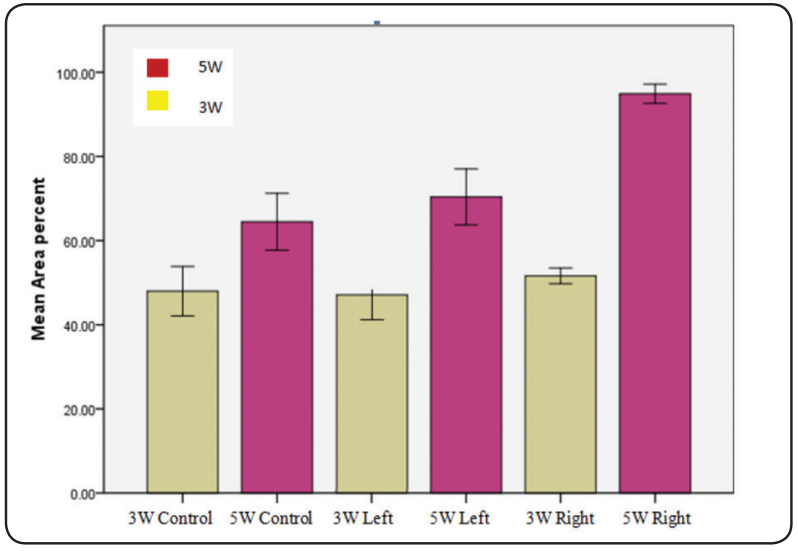

Fig. (6) Bar chart showing mean bone area percent in different groups at both observation periods.

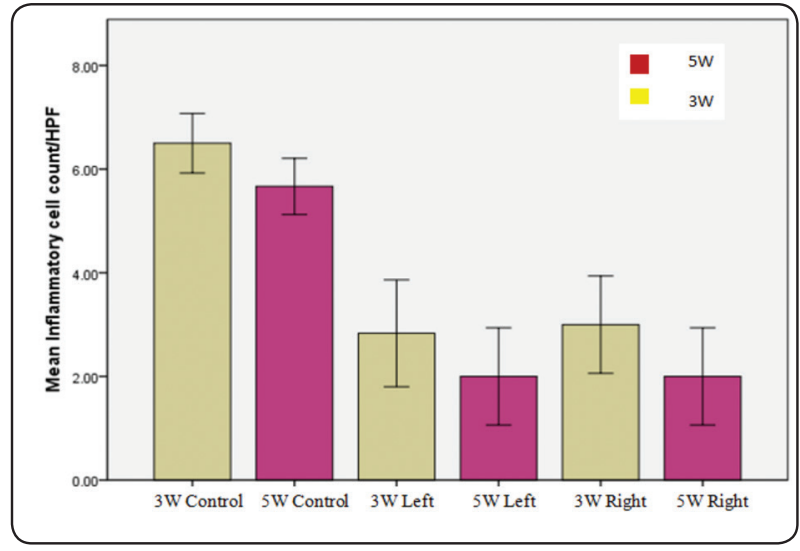

Fig. (7): Bar chart showing mean inflammatory cell count per high power field (/HPF) in different groups at both observation times 
TABLE (5) Comparison between both observation times within the same group (paired t test) and comparison between all groups at different times (ANOVA test)

\begin{tabular}{|c|c|c|c|c|c|c|c|}
\hline & & Mean & Std. Dev & Mean difference & Std Dev of difference & $\mathrm{T}$ & $\mathrm{P}$ \\
\hline \multirow{7}{*}{ Area percent } & 3Weeks (control) & $47.97^{\mathrm{c}}$ & 5.61 & \multirow{2}{*}{-16.50} & \multirow{2}{*}{10.87} & \multirow{2}{*}{3.72} & \multirow{2}{*}{$0.01 *$} \\
\hline & 5Weeks (control) & $64.46^{\mathrm{b}}$ & 6.44 & & & & \\
\hline & 3Weeks-L & $44.76^{\mathrm{d}}$ & 2.52 & \multirow{2}{*}{-25.61} & \multirow{2}{*}{6.17} & \multirow{2}{*}{22.06} & \multirow{2}{*}{$0.00 *$} \\
\hline & 5 Weeks-L & $70.37^{\mathrm{b}}$ & 6.33 & & & & \\
\hline & 3 Weeks-R & $51.61^{\mathrm{c}}$ & 1.76 & \multirow{2}{*}{-43.28} & \multirow{2}{*}{3.05} & \multirow{2}{*}{34.81} & \multirow{2}{*}{$0.00 *$} \\
\hline & 5 weeks-R & $94.9^{\mathrm{a}}$ & 2.17 & & & & \\
\hline & \multicolumn{7}{|c|}{ Comparison of all groups: $\mathrm{F}=201.79, \mathrm{P}=0.00^{*}$} \\
\hline \multirow{7}{*}{$\begin{array}{c}\text { Number of } \\
\text { Inflammatory } \\
\text { cells/HPF }\end{array}$} & 3Weeks (control) & $6.50^{\mathrm{a}}$ & .55 & \multirow{2}{*}{.83} & \multirow{2}{*}{.75} & \multirow{2}{*}{0.71} & \multirow{2}{*}{$0.44 \mathrm{~ns}$} \\
\hline & 5Weeks (control) & $5.67^{\mathrm{a}}$ & .52 & & & & \\
\hline & 3Weeks-L & $2.83^{\mathrm{b}}$ & .98 & \multirow{2}{*}{.83} & \multirow{2}{*}{.41} & \multirow{2}{*}{0.15} & \multirow{2}{*}{$0.31 \mathrm{~ns}$} \\
\hline & 5 Weeks-L & $2.00^{\mathrm{b}}$ & .89 & & & & \\
\hline & 3Weeks-R & $3.00^{\mathrm{b}}$ & .89 & \multirow{2}{*}{1} & \multirow{2}{*}{.11} & \multirow{2}{*}{0.34} & \multirow{2}{*}{$0.34 \mathrm{~ns}$} \\
\hline & 5 weeks-R & $2.00^{\mathrm{b}}$ & .89 & & & & \\
\hline & \multicolumn{7}{|c|}{ Comparison of all groups: $\mathrm{F}=34.27, \mathrm{P}=0.00 *$} \\
\hline
\end{tabular}

Significance level $P \leq 0.05$, * significant

Tukey's post hoc test: Within the same comparison: means sharing the same superscript letter are not significantly different

\section{3- High performance liquid chromatography (HPLC) Results:}

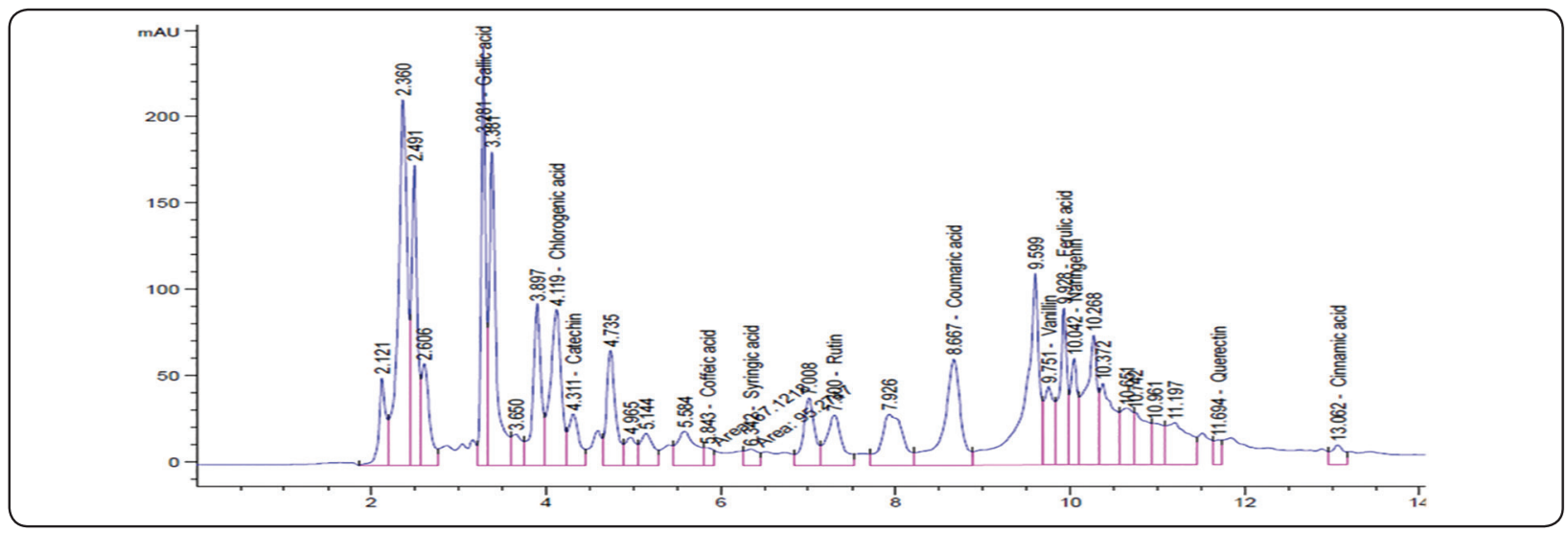

Fig. (8): Representative HPLC chromatogram of Moringa leaf powder and extract mixture showing flavonoid and polyphenol peaks 
TABLE (6): Polyphenols/ flavonoid contents in both water extract \& powder and water extract mixture.

\begin{tabular}{|l|l|l|}
\hline $\begin{array}{l}\text { Polyphenols/ } \\
\text { Flavonoid contents }\end{array}$ & $\begin{array}{l}\text { Water extract } \\
\text { (Injection) } \\
\text { Conc. }(\boldsymbol{\mu g} / \mathbf{~ m l})\end{array}$ & $\begin{array}{l}\text { Mixture: (Powder } \\
\text { and water extract) } \\
\text { Conc. }(\boldsymbol{\mu g} / \mathbf{~ m l})\end{array}$ \\
\hline Gallic acid & 108.02 & $594.08^{*}$ \\
\hline Rutin & 153.10 & 479.11 \\
\hline Chlorogenic acid & $189.41^{*}$ & 458.22 \\
\hline Catechin & 100.47 & 383.74 \\
\hline Naringenin & 123.34 & 206.10 \\
\hline Ferulic acid & 161.02 & 176.73 \\
\hline Querectin & 56.08 & 134.64 \\
\hline Coumaric acid & 3.53 & 92.09 \\
\hline Vanillin & 60.14 & 77.13 \\
\hline Syringic acid & 16.01 & 24.41 \\
\hline Coffeic acid & 13.43 & 18.91 \\
\hline Cinnamic acid & 2.46 & 9.38 \\
\hline
\end{tabular}

\section{DISCUSSION}

Natural biomaterials attracted attention in the past few years, to defend against non-communicable diseases (Diabetes-Hypertension-Cancer) likely related to lifestyle performance and type of food consumption. Plant based food, like vegetables and fruits gained attraction. Moringa as a type of natural herb of low cost, easy to grow in many countries showed superior applications. Moringa oleifera plant parts (leaf-flower-seed-pods-stem) possess many uses. MO leaf gained upper hand in all recent studies because of high phytochemical contents (mainly polyphenols). Yet, differences in seasonal pick, maturation stage, solvent used and extraction methods had an essential role on the bio-components kinds and amounts. ${ }^{10,12.13 .18,19}$ For example, A study conducted on differences between chemical constitutes of MO leaf in China and India results showed some differences of ingredients. ${ }^{6,10}$ From all above, quality control method is demanded for standardization, to access the active ingredients. Current study utilize dried leaf powder by conventional method as stated in material and method section to preserve as a much as possible the active ingredients and to be used for long time without loss of value. ${ }^{7}$ Regarding the choice of solvents water being the safest, used to prepare the liquid extract. ${ }^{17}$ Moreover, confirmed high antibacterial activity against main pathologic flora (Gram positive and negative) due to presence of phytochemicals besides its analgesic and antiinflammatory properties. . $^{8,18,20,21}$

A study confirmed cytotoxicity for ethanolic extracts over the water extract. ${ }^{17}$ Diverse opinions on difference between levels of phytochemicals in different solvents (Ethanolic, Methanolic and Water extracts). Most experiments confirmed ethanol extract upper hand..$^{6,717,18,22-28}$ While, Kwon research confirmed superior results for water extract of moringa over ethanolic extract (Table 2). ${ }^{16}$

Previous studies confirmed the tissue preservation of M. oleifera leaf ethanolic extracts, for example it protected rats against the hepatotoxicity of various drugs, ${ }^{9}$ and increased cell proliferation and cell migration of human dermal fibroblasts. ${ }^{29}$ A study 2010 was the first described using MO leaf ethanol extract in feeding ovariectomized rat and concluded osteoprotection, ${ }^{23}$ this was confirmed by a study conducted on osteoporotic women which concluded increased bone density after consumption of MO leaf. $^{30}$

Further researches demonstrated MO leaf local effects on bone healing and osteoblast cells, started by an invivo study using different part of MO extracts (leaf-fruit-flower) on osteoblast cells, this results demonstrated negative effect of leaf extract on osteoblast and supports the fruit and flower positive effect. ${ }^{25}$ Afterwards, five studies using rat as animal model, extracting its lower incisors teeth to create a fresh extraction socket. All the studies used MO leaf $2 \%$ ethanol or methanol 
extracts in treating the fresh sockets. They all came to an agreement that the treatment increases the number of osteoblasts, decrease the number of osteoclasts, which shifts the remodeling process toward bone formation. Going into some details, the MO leaf extract increased alkaline phosphatase activity, collagen type I expression, osteocalcin and transforming growth factor beta $\left(\mathrm{TGF}_{\mathrm{B}}\right)$ expressions (responsible for deposition of bone matrix ), besides it decreased number of Rankle expression ${ }^{1,24,29,31,32}$ Moreover, a study conducted on upper central extraction socket in a rat model 2018 using mate tea intra-gastric lavage concluded positive effects on alveolar healing at 28 days postoperatively. ${ }^{4}$

Our study uniquely used high concentration of water extract (11.7\%) suggested to be comparable to ethanol osteoprotective property. Moreover, using large animal model (dog) for the first time with MO leaf. The dog is likely to have comparable bone metabolism to human. Supposed osteoconductive property of the mixture (aqueous extract and MO leaf powder) allow new bone formation. The mixture was easy to handle, and easy to consolidate.

The liquid extract could be easily injected supposed to provide indirect osteoinductive property. The injection was easily delivered in the first two weeks postoperatively. While after that date the wound could not accept any injections. The newly formed osteoid bone which was confirmed in Masson trichome stain (Fig.5) showed increased value in the right side with non-significant results at 3 weeks, while at 5 weeks demonstrated significant results. All MO treated groups showed significant decrease in number of inflammatory cells.

Moringa oliefera leaf ethanolic extract 2\% on top of osteoconductive matrix demineralized freeze bovine bone xenograft (DFBBX) induced osteoblasts stimulation. This is on account of phytochemical contents. ${ }^{29}$ This was concurrent with an invivo study conducted on the effect of Moringa oleifera Lam. leaf ethanolic extract on osteogenic differentiation of porcine bone marrow derived mesenchymal stem cells showed positive results..$^{33}$ This was confirmed in current study, MO leaf water extract $11.7 \%$ repeated injections increased bone area percent and decrease inflammatory cells significantly at 5 weeks.

Moringa oleifera leaf powder and extract mixture has mainly gallic acid, rutin, chlorogenic acid, catechin and Naringenin. While, Moringa oleifera leaf extract contains cholorogenic acid, ferulic acid, rutin, Naringenin, garlic acid and quercetin. Polyphenols decrease inflammatory mediators, such as histamine, and cytokines. Consequently decrease bone resorption ${ }^{29,34-36}$ Chlorogenic acid, rutin and ferulic acid had osteoprotective function by promoting bone mineral density. ${ }^{37-41}$ Gallic acid in an in-vivo study showed positive effects around implants ${ }^{35}$ Catechin, green tea polyphenols also promotes osteogenesis ${ }^{42}$ Syringic acid stimulates stem cells into osteoblasts, and it could be an osteogenic compound. ${ }^{44}$ Cinnamic acid could be a part of osteogenic stimulant composite. ${ }^{45}$ Naringenin had stimulant effects on bone similar to estrogen. ${ }^{46}$ All these components could be the possible cause for osteoblast stimulation to form new bone. In general, the importance of other components could not be neglected (Table 1,2) such as minerals, and vitamins. Supposed synergy between these components could be the secret.

Within the inherent limitations of this animal study, it was concluded that Moringa oliefera powder and extract mixture in fresh extraction sockets increased bone area percent, but the increase is not significant. While repeated injections of MO leaf water extract of $11.7 \%$ concentration once a week for two weeks, affects bone area positively specially at 5 weeks postoperatively. Supposed sustain release of the confirmed bioactive polyphenolic compounds was the cause.

\section{RECOMMENDATIONS}

Study the difference between osteostimulant activity of both extracts of same concentration 
(water and ethanol) on the same animal model. Besides, the difference between fruit and leaf extract of the same solvents. Moreover, using non-invasive methods for bone assessment (Infra-red mapping for example). Repeated injection need slandered calculations of sustain release.

\section{REFERENCES}

1. Kresnoadi U, Rahmania PN, Caesar HU, Djulaeha E, Agustono B, Ari MD. The role of the combination of Moringa oleifera leaf extract and demineralized freeze-dried bovine bone xenograft (xenograft) as tooth extraction socket preservation materials on osteocalcin and transforming growth factor-beta 1 expressions in alveolar bone of Cavia cobaya. J Indian Prosthodont Soc 2019; 19:120-5

2. Maiorana C, Paolo Poli P, Deflorian M, Testori T, Mandelli F, Nagursky H, Vinci R. Alveolar socket preservation with demineralised bovine bone mineral and a collagen matrix. J Periodontal Implant Sci. 2017 Aug;47(4):194210

3. Suhono R, Pramono C, Asmara D. Effect of soybean extract after tooth extraction on osteoblast numbers. Dental Journal .2011;44(2):111-116

4. Brasilino MDS \& Stringhetta-Garcia CT\& Pereira CS\& Ferreira Pereira AA \& Stringhetta K \& Leopoldino AM \& Crivelini MM \& Ervolino E \& Dornelles RCM\& tevanato Nakamune ACDM\& Chaves-Neto A H: Mate tea (Ilex paraguariensis) improves bone formation in the alveolar socket healing after tooth extraction in rats. Clin Oral Invest (2018) 22:1449-1461

5. Managutti A, Shah D, Patel J, Puttanikar N, Shah D, Managutti S. Evaluation of clinical efficacy of cissus quadrangularis in pain management and bone healing after implant placement - a pilot study. Med. Res. Chron., 2015, $2(5), 618-625$

6. Koul B and Chase N. Moringa oleifera Lam.: Panacea to several maladies J. Chem. Pharm. Res., 2015, 7(6):687-707

7. Mahmood KT, Mugal and Ul Haq I. Moringa oleifera: a natural gift-A review. J. Pharm. Sci. \& Res. Vol.2 (11), 2010, 775-781

8. Abd Rani NZ, Husain K and Kumolosasi E (2018) Moringa Genus: A Review of Phytochemistry and Pharmacology. Front. Pharmacol. 9:108. doi: 10.3389/fphar.2018.00108

9. Stohs SJ and Hartman MJ: Review of the Safety and Ef- ficacy of Moringa oleifera. Phytother. Res. 29: 796-804 (2015)

10. Lin H, Zhu H, Tan J, Wang H, Wang Z, Li P, Zhao C, and Liu J. Comparative Analysis of Chemical Constituents of Moringa oleifera Leaves from China and India by UltraPerformance Liquid Chromatography Coupled with Quadrupole-Time-Of-Flight Mass Spectrometry. Molecules 2019, 24, 942

11. Patel C, Ayaz RM, Parikh P. Studies on the Osteoprotective and Antidiabetic Activities of Moringa Oleifera Plant Extract. IOSR Journal of Pharmacy. Volume 5, Issue 5 (May 2015), PP. 19-22

12. Vergara-Jimenez, M.; Almatrafi, M.M.; Fernandez, M.L. Bioactive Components in Moringa oleifera Leaves Protect against Chronic Disease. Antioxidants 2017, 6, 91 . [CrossRef] [PubMed]

13. Lin M, ZhangJ, ChenX. Bioactive flavonoids in Moringa oleifera and their health-promoting properties. Journal of Functional Foods 47 (2018) 469-479.

14. Khor KZ, Lim V, J. Moses E, and Abdul Samad N. The In Vitro and In Vivo Anticancer Properties of Moringa oleifera. Evidence-Based Complementary and Alternative Medicine. Volume 2018, Article ID 1071243, 14 pages

15. Rai, A.; Hameed, A.; Noreen, R. Antioxidant Potential and Biochemical Analysis of Moringa oleifera Leaves. Int. J. Agric. Biol. 2017, 19, 941-950. [CrossRef]

16. Kwon YR, Youn KS. Antioxidant activity and physiological properties of Moringa (Moringa oleifera Lam.) leaves extracts with different solvents. Korean J. Food Preserv. 21(6), 831-837 (2014)

17. Sanganna B, Chitme HR, Yrunda K, and Jamadar MJ. 2016 Antiproliferative and antioxidant activity of leaves extracts of moringa oleifera. Int J Curr Pharm Res, Vol 8, issue $4,54-56$

18. Nweze, Nkechinyere Onyekwere and Nwafor, Felix. Phytochemical, Proximate and Mineral Composition of Leaf Extracts of Moringa oleifera Lam. from Nsukka, SouthEastern Nigeria (IOSR-JPBS) Volume 9, Issue 1 Ver. VI (Feb. 2014), PP 99-103

19. Makita C, Chimuka L, Steenkamp P, Cukrowska E, Madala E. Comparative analyses of flavonoid content in Moringa oleifera and Moringa ovalifolia with the aid of UHPLC-qTOF-MS fingerprinting. South African Journal of Botany 105 (2016) 116-122 
20. M.R. Sulaiman, Z.A. Zakaria, A.S. Bujarimin, M.N. Somchit, D.A. Israf \& S. Moin (2008) Evaluation of Moringa-oleifera Aqueous Extract for Antinociceptive and Anti-Inflammatory Activities in Animal Models, Pharmaceutical Biology, 46:12, 838-845, DOI: $10.1080 / 13880200802366710$

21. El-Gammal RE, Abdel-Aziz M E and Darwish MS. Utilization of Aqueous Extract of Moringa oleifera for Production of Functional Yogurt. J. Food and Dairy Sci., Mansoura Univ., Vol. 8 (1): 45- 53, 2017

22. Fitriana WD, Ersam T, Shimizu K, and Fatmawati S. Antioxidant Activity of Moringa oleifera Extracts. Indones. J. Chem., 2016, 16 (3), 297 - 301.

23. Burali SC, Kangralkar V, Sravani O and Patil SL The beneficial effect of ethanolic extract of moringa oleifera on osteoporosis, International journal of pharmaceutical applications, 1(1), 2010, 50-58.

24. Soekobagiono S, Alfiandy A, and Dahlan A. RANKL expressions in preservation of surgical tooh extraction treated with Moringa (Moringa oleifera) leaf extract and demineralized freeze-dried bovine bone xenograft. Dental J. 2017 September; 50(3): 149-153

25. Patel C, Rangrez A, Parikh P. The anti-osteoporotic effect of Moringa oliefera on osteoblastic cells: SaOS 2. (IOSRJPBS). Volume 5, Issue 2 (Jan. - Feb. 2013), PP 10-17

26. Idris A and Abubakar U. Phytochemical and antibacterial investigations of moringa (Moringa oleifera) leaf extract on selected bacterial pathogens. Journal of Microbiology and Antimicrobials Vol. 8(5), pp. 28-33, July 2016.

27. Ojo NA., Simon J, Adawaren EO, Sodipo OA, Madziga HA, Yahi D, Mbaya YP, Dibila HM and Telta AD. Chemical components and effect of aqueous extract of moringa oliefera leaves on biochemical parameters in rats. Vom Journal of Veterinary Science Vol. 10, 2015: 114 - 126.

28. K.H. El-Kholy, Safaa A. Barakat, W.A. Morsy, K. AbdelMaboud, M.I. Seif El naser and Mervat N. Ghazal. Effect of Aqueous Extract of Moringa oleifera Leaves on Some Production Performance and Microbial Ecology of the Gastrointestinal Tract in Growing Rabbits. Pakistan Journal of Nutrition. Volume 17 (1): 1-7, 2018

29. Soekobagiono, Salim S, Eka Hidayati H, and Mundiratri K. Effects of Moringa oleifera leaf extract combined with DFBBX on type-1 collagen expressed by osteoblasts in the tooth extraction sockets of Cavia cobaya. Dental J. 2018 June; 51(2): 86-90.
30. Brown $\mathbf{J}$ et al thesis. Effect of moringa oleifera on bone density in post-menopausal women. May 2016 Exercise Science Master's Program. Department of Health Science.P1-56

31. Rostiny R, Djulaeha E, Hendrijantini N, Pudijanto A. The effect of combined Moringa oleifera and demineralized freeze-dried bovine bone xenograft on the amount of osteoblast and osteoclast in the healing of tooth extraction socket of Cavia cobaya. Dent J (Maj Ked Gigi). 2016; 49(1): 37-42.

32. Engsuwana J, Waranuch N, Limpeanchob N, Ingkaninana K. HPLC methods for quality control of Moringa oleifera extract using isothiocyanates and astragalin as bioactive markers. ScienceAsia 43 (2017): 169-174.

33. Marupanthorn K, and Kedpanyapong W. The Effects of Moringa Oleifera Lam. Leaves Extract on Osteogenic Differentiation of Porcine Bone Marrow Derived Mesenchymal Stem Cells. 4th International Conference on Advances in Agricultural, Biological \& Ecological Sciences (AABES-16) Dec. 1-2, 2016 London (UK)

34. Jiaying G. Mechanistic studies on the osteogenic effects of dietary flavonoids in cultured osteoblasts: potential drug development against osteoporosis. Thesis. Hong Kong: Hong Kong University of Science and Technology; 2011. p. $146-50$.

35. Cazzola, Ferraris S, Prenesti E, Casalegno V and Spriano S. Grafting of Gallic Acid onto a Bioactive Ti6A14V Alloy: A Physico-Chemical Characterization Martina

36. Vongsak, B.; Sithisarn, P.; Gritsanapan, W. Simultaneous HPLC quantitative analysis of active compounds in leaves of Moringa oleifera Lam. J. Chromatogr. Sci. 2014, 52, 641-645. [CrossRef] [PubMed]

37. Min J, Yuan Z, Zhang Q, Lin S, KaiWang and Luo J. Analysis of anti-osteoporosis function of chlorogenic acid by gene microarray profiling in ovariectomy rat model. Bioscience Reports (2018) 38 BSR20180775

38. Moetazza M. Alshafei, Seham S. Kassem, Manal M. Ramadan, Emtenan M. Hanafi, Maha M. Saber, Lobna M. Saber and Aliaa Elgendy. Innovative Food Supplement of Functional Seeds Mixture Improved Bone Mineral Density in Menopausal Egyptian Women. Int. J Pharmacol. 13(8):1055-1062, 2017

39. Pereira YCL, Issa JPM, Watanabe E, Nascimento GC, Iyomasa MM, et al. (2018) The Therapeutic Use of Propolis Extract in Alveolar Bone Contaminated with Bacterial Endotoxin. Dentistry 8: 473. doi:10.4172/2161-1122.1000473 
40. Elisa Torre. Molecular signaling mechanisms behind polyphenol-induced bone anabolism. Phytochem Rev (2017) 16:1183-1226

41. Horcajada-Molteni MNL, Crespy V, VéRonique Coxam, Marie-Jeanne Davicco, Christian RéMéSy, And JeanPierre Barlet. Rutin Inhibits Ovariectomy-Induced Osteopenia in Rats. JOURNAL OF BONE AND MINERAL RESEARCH Volume 15, Number 11, 2000

42. Chu C, Deng J, ManJ, and Qu Y. Green Tea Extracts Epigallocatechin-3-gallate for Different Treatments. BioMed Research International. Volume 2017, Article ID 5615647, 9 pages

43. Kizilda GA et al., Therapeutic effects of caffeic acid phenethyl ester on alveolar bone loss in rats withendotoxin-induced periodontitis, Journal of Dental Sciences, https://doi.org/10.1016/j.jds.2019.03.011
44. B. Arumugam \& K. Balagangadharan \& N. Selvamurugan. Syringic acid, a phenolic acid, promotes osteoblast differentiation by stimulation of Runx 2 expression and targeting of Smad7 by miR-21 in mouse mesenchymal stem cells. Journal of Cell Communication and Signaling (2018) 12:561-573

45. Kanitkar A, Chen C, Smoak M, Hogan K, Scherr T, Aita $\mathrm{G}$ and Hayes D. In vitro characterization of polyesters of aconitic acid, glycerol, and cinnamic acid for bone tissue engineering. Journal of Biomaterials Applications 2015, Vol. 29(8) 1075-1085

46. Swarnkar G, Sharan K, Siddiqui JA, Mishra JS, Khan K , Khan MP, Gupta V, Rawat P, Maurya R., Anil K Sabyasachi Sanyal2 and Naibedya Chattopadhyay1A naturally occurring Naringenin derivative exerts potent bone anabolic effects by mimicking oestrogen action on osteoblasts. British Journal of Pharmacology (2012) 165 1526-1542 